\title{
A conversation with George Church
}

$T_{\text {h }}$ he geneticist, innovator, and entrepreneur, George Church of Harvard and MIT, developed the methods for the first genome sequencing and his subsequent work has brought down the price of sequencing over 10-million-fold. His was one of the two research groups that first got CRISPR-Cas9 to work for precise gene editing in human cells by a homologous recombination and he has been behind countless other scientific innovations and disruptions, specifically in the world of precision genome sequencing. To see Church (Figure 1) talk about the ethical implications of reversing aging, and how his first experiment presaged the movie Little Shop of Horrors, see the full interview on the JCI website at http://jci.org/videos/cgms.

JCI: What were you like as a kid?

Church: I had three fathers; the first one was in the Air Force and had a variety of jobs thereafter but was only with me for the first few months. I remained in Florida getting an early terrible education. That was a defining feature, but the result was that I got a lot of extracurricular experience. I loved nature. I spent a lot of time on the mudflats and swamps and with living creatures. My third father was a physician; I was heavily influenced by his medical bag that he carried around on house calls, which even then was quite an anachronism.

I didn't know any scientist or any engineers growing up. I didn't have a science teacher until seventh grade and even then, she was part-time because the school didn't want to make a commitment to such a radical topic. I left Florida to go to Massachusetts when I was 13 for boarding school at Phillips Academy. My third father had been there for two years. He didn't particularly like it, but it was his gut feeling that I would. It was four years of heaven. It totally challenged me and stimulated me to study all kinds of things like art, photography, and athletics, but mostly science and math.

One of the first things I sought out in ninth grade was a computer, as Phillips had a connection with the Dartmouth computer time share, which nobody used. I found that it was in a basement with no chairs, no furniture, and I just started working on it.

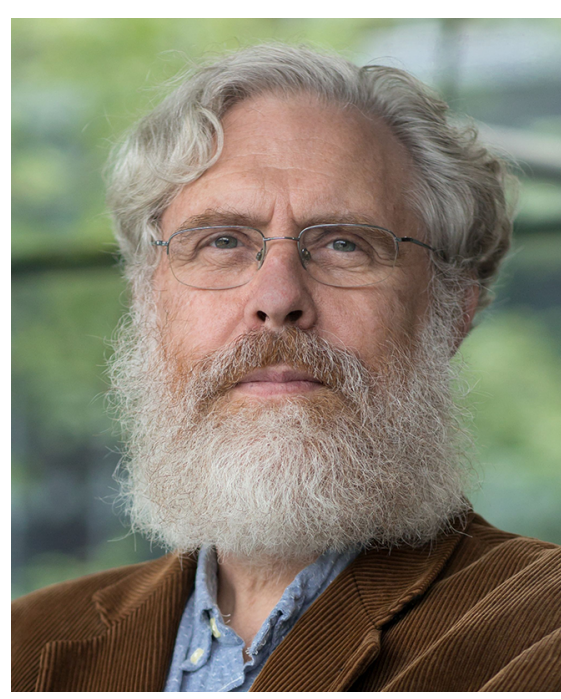

Figure 1. George Church. Image credit: Wyss Institute at Harvard University.

JCI: What led you to want to do undergraduate degrees in chemistry and zoology?

Church: I never wanted to specialize. As it turned out I was fairly strong in math and physics, but zoology and chemistry were what I ended up doing. In my spare time I did research in crystallography, which really did combine all of the fields in an obligatory way.

I had been looking for a part-time job and finally one caught my eye. I walked in for the interview and here's this assistant professor, Sung-Hou Kim, who is quite small in comparison to the model that he was building. He's about half the size of this model for transfer RNA, which was done back then with wrenches and half-silvered mirrors and electron density maps. After figuring out that it required Fourier transforms and computers and deep knowledge of chemistry, and had implications for medicine, I thought it was the whole package. I was in love. I would have flunked out of undergrad but I managed to finish early; instead I flunked out of graduate school at Duke.

JCI: How did you manage to then go to Harvard Graduate School for your PhD?

Church: It sounds mysterious at first how you can recover from a complete flunk. But I had published five papers while I was flunking out, and I had been accepted to Harvard
Graduate School before, so they, perhaps, felt like I couldn't have gone that much downhill overnight. They took a chance on me. They never said so, and they never acted like there was anything out of the ordinary. I buckled down, tried to become more mature overnight. I figured I'd better not flunk out twice.

JCI: How did you end up in the Wally Gilbert lab doing research on genetics and genomics?

Church: As it turned out, Wally Gilbert, Mark Ptashne, Steve Harrison, Don Wiley, and others were all interested in crystallography. I was one of the few incoming students who had extreme experience in crystallography. But I sort of felt, "been there, done that." I felt that every other field of biology, and chemistry to some extent, didn't have what crystallography had - solid biophysics foundations, computers, or automation. I set out to take the lessons I learned from crystallography and apply them to adjacent fields: DNA, RNA, proteins, and eventually synthetic biology.

My $\mathrm{PhD}$ thesis was a hodgepodge of two things, one having to do with yeast and one having to do with mammalian immunoglobulin genes. I tried to stitch it together as "functions of introns." Introns had just been discovered and everybody thought it was junk DNA. The part on immunoglobulins was not just that, it was also on a new sequencing method, what we call "genomic sequencing."

Wally and many people in his lab were not just interested in sequencing but in applying sequencing to methylation and protein-DNA interactions. I did that, but on a genomic scale; it wasn't just the scale, it was completely rethinking the way that we collected data. It was more of an emphasis on re-probing and imaging than on electrophoresis, which I think directly led me to what would become fluorescent reprobing-based imaging, which was the first of the "next-gen sequencing."

JCI: Did you think that your path was to be academic or entrepreneurial?

Church: I was not very thoughtful about my career at any point. Probably still not, but definitely not then. I was doing entrepreneurial things, before I knew of Biogen, which was Wally's first company. I had written software in ' 78 to do automatic DNA sequencing. I actually did it in a crystallography lab using a new instrument that they were intimidated to set up. I said, “I'll use my rotation to set 
it up for you, if I get to use it for something non-crystallographic for a few weeks." I wrote the software and then I took it to Bio-Rad; the point is that I was a mixture of academic and entrepreneur. I wasn't really concerned about what I was going to do long term.

JCI: What made you decide to do a postdoc with Gail Martin, an embryonic stem cell pioneer?

Church: I had already been working with Gail, and had committed to doing a postdoc in her lab before I went to Biogen. Part of what I'd done in my thesis was studying how B cells develop different progenitor stages. I thought the ultimate progenitor stage would be embryonic. But I didn't know how to get embryos. Gail provided the world's first embryonic stem cells (called PSA-1).

I started thinking about homologous recombination, but didn't get to it [during my postdoc], and I thought it would be interesting research to do with Gail. Another motivation was that my girlfriend had applied to a lab at Stanford. She eventually became my wife and now we've been together for 40 years and have two grandchildren.

JCI: How did you end up back at Harvard for your first assistant professorship?

Church: The same woman, Ting Wu, decided about four months in that she didn't like her project at Stanford, and so she started her own institute, got her own grants, and was acting like an assistant professor back on the East Coast. I cleaned up my loose ends as fast as I could and cut my postdoc short. I was very lucky that Harvard would take me with such a pathetic postdoctoral career. I basically had done nothing post-Biogen that was publishable, and my work was all over the map, from embryonic stem cells to crystallography to a half-baked Genome Project. I have to say Harvard continually picked up the pieces of my failed career and did it again when I came up for tenure. At least three times they've saved my bacon when I was not doing such a good job of saving myself.

JCI: You were one of the few people instrumental in getting the Human Genome Project started, but it's been noted that you didn't think enough was accomplished with the initial \$3B investment.

Church: Oh yes. I was in the first discussions in 1984, which were Department of Energy-centric. We thought we could do it for a dollar per base, but I was immediately disappointed because I wanted to bring the price down radically and to do something that would be clinically valuable. I thought the goals were misaligned, so I became a conscientious objector of my own project and spent the whole time during the genome project developing new sequencing technology.

JCI: Do you think every human should have their genome sequenced?

Church: I don't know if they should, but I think they should have the opportunity. What we need is to educate people about the value and now we also have privacy tools that can make it so that there's essentially no risk, and wherein you retain control of your information.

JCI: Has one of the main stumbling blocks been the privacy issues? You have famously put all of your medical records and your genome in the public domain. Has anyone tried to steal your identity?

Church: There haven't been any negative consequences of it - but that's not an argument that it is safe. I didn't do it to show that, "Hey, join me with the killer whales, the water's safe!" We need both the highly private version, and a highly public version and we only need a few volunteers for the highly public version, because there's a lot of things you can do with a small number of people.

JCI: Synthetic biology is another main thrust in your lab. Some of the many applications in your lab have been gene drives in mosquitoes to eradicate malaria, to using CRISPR to eliminate 62 different porcine endogenous retrovirus genes at once toward the goal of using pig organs for human transplantation. And then, one that has captured the public's attention: using CRISPR to transplant woolly mammoth genes into African elephants. Some of this sounds like science fiction.

Church: Nearly everything we touch seems to go swiftly from science fiction to normal. Millions of families each year use noninvasive prenatal testing, which is a consequence of next-gen sequencing. With synthetic biology, there's a growing number of green chemistry applications, from flavors, fragrances, and complex polymers that are made biologically rather than with petroleum or high temperatures; this list is just going to expand. I have speculated that essentially everything that we can currently manufacture today without biology, we will be able to manufacture with biology and with potential advantages; biology is intrinsically atomically precise and it's scalable to cover the whole planet essentially for free. I think that we're in a truly revolutionary phase and that we need to be very thoughtful.

JCI: Including using CRISPR on humans?

Church: We are already using CRISPR and other gene therapies on humans. Not only ongoing human clinical trials, there are now three approved gene therapies - none of them are CRISPR - but CRISPR is approved for clinical trials. I think what you're alluding to is this: Is there a barrier between doing it in adults, children, fetuses, embryos without germline, embryos with germline, and so forth? These are under discussion, and now even the most off-the-table things have been tested. We've got reports of babies with an enhanced germline. The experiment has been done, but there are many more that could be done. It's a matter of having that discussion and seeing whether the benefits outweigh the risks.

JCI: What do you think the next 10 years holds for your research?

Church: I am addicted to technology development. We're getting more into biomanufacturing things containing inorganic materials, like computers. I'm interested in space genetics and sending objects or entities to Alpha Centauri that can radio back... the biological engineering of such objects. I'm interested in biomanufacturing the moral equivalent of electronics, which might be actual, fully biological brains that can compete with artificial intelligence. I'm also still doing some of the same things I was doing as a teenager, like crystallography and transfer RNA - still two of my favorite things.

JCI: If you could not be a scientist, what do you think you would have taken up?

Church: The cheat answer is engineering. In fact, it took me years to realize I was actually more of an engineer than I was a scientist. But artist would be the next choice. I think that that's also a cheat because "practical arts" was a term for engineering at one point. My first semester in college, I was a cinematography major, and when I first started looking for a lab, one of the things I liked about the crystallography lab is that they actually had a scanner where you could scan in photographs. I had been looking for such a scanner for years because I thought, "Wouldn't it be cool if you could scan a photograph and manipulate it on a computer?" And just about everybody asked, "Why would you want to do that?"

\section{Ushma S. Neill}

